\title{
LITERATURA E POLÍTICAS EDUCACIONAIS: UMA ABORDAGEM SOCIAL A PARTIR DO CONTO "CAMINHÃO DE ARROZ" DE BERNARDO ÉLIS
}

\author{
Literature and educational policies: a social approach from the tale "Caminhão \\ de Arroz" by Bernardo Élis
}

\section{José Elias Pinheiro Neto}

https://orcid.org/0000-0001-9574-6451

Universidade Estadual de Goiás, Programa de Pós-graduação Stricto Sensu em Língua, Literatura e Interculturalidade, Goiás, GO, Brasil. 76600-000 - coord.poslli@ueg.br

\author{
Antonio Oliveira \\ https://orcid.org/0000-0003-2588-7368 \\ Universidade Estadual de Goiás, Curso de Letras, Ituporanga, GO, Brasil. 76680-000 - \\ dir.itapuranga@ueg.br
}

\begin{abstract}
Resumo: O objetivo deste trabalho é perceber no conto Caminhão de Arroz, publicado em 1962, na coletânea de contos Ermos e Gerais, de Bernardo Élis, escritor renomado de Goiás, possibilidades de letramento literário que pode propiciar ao leitor uma reflexão epistemológica sobre si e sobre o meio social. Além disso, demonstrar a necessidade de pensar sobre o ensino de literatura no sistema educacional atual, uma vez que a literatura deve ser voltada para o processo de humanização do ser humano (CANDIDO, 1995). A análise se refere especificamente a um estudo sociológico confrontada com objeto da pesquisa: o conto. A narrativa envolve uma personagem que busca na cidade de Anápolis-GO a irmã desparecida. Ela é uma sertaneja e em sua primeira aparição está na carroceria de um caminhão com uma carga de arroz, as pessoas da cidade confundem a protagonista com uma das sacas e totalmente desajeitada desembarca procurando informação a respeito de sua parente que não vê por muito tempo. Há em sua busca frustrada o sofrimento com zombarias e desprezo das pessoas da cidade e, ainda, a personagem sente tristeza e amargura por se ver em um enorme espelho e não conseguir se reconhecer nele. A trama aponta uma reflexão em relação ao confronto meio rural e cidade e a à disparidade social marcante da história de Goiás, configurada pela forma de menosprezo de como se dão as relações entre os citadinos e os 'roceiros'. Por fim, a obra assume um caráter universal dada a angústia social da personagem que acaba por representar o ser humano de uma forma geral. Tais observações são pressupostos para a contextualização do ensino de literatura na atualidade.
\end{abstract}

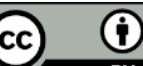

Esta obra está licenciada sob uma Creative Commons - Atribuicão 4.0 
Palavras-chave: Literatura. Bernardo Élis. Social.

Abstract: This paper has as objective to realize in the short story Caminhão de Arroz, published in 1962, in the collection of short stories Ermos e Gerais, by Bernardo Élis, reputed writer from Goiás state, possibilities of literary literacy that can provide the reader with an epistemological reflection on himself and about the social environment. In addition, demonstrating the need to think about the teaching of literature in the current educational system, once literature has tuned to the humanization process of the human being (CANDIDO, 1995). The analysis refers specifically to a sociological study confronted with the research object: the short story. The narrative involves a character who search in the city of Anápolis-GO for the missing sister. She is a country girl and in her first appearance is in the truck body with a load of rice, the townspeople confuse the protagonist with one of the bags and totally clunky disembarks looking for information about her unseen relative. There is in his frustrated search the suffering with mockery and contempt of the people of the city, and yet, the character feels sadness and bitterness to see himself in a huge mirror and unable to recognize himself in it. The plot points to a reflection on the confrontation between the countryside and the city and the striking social disparity in the history of Goiás, configured by the disregard of how the relations between the city and the 'roceiros' take place. Finally, the text assumes a universal character given the social anguish of the character that ends up representing the human being in a general way. Such observations are presuppositions for the contextualization of literature teaching today.

Keywords: Literature. Bernardo Élis. Social.

\section{Considerações iniciais}

Comumente o ensino de literatura é questionado no meio educacional. Sugestões de métodos e novas abordagens tentam desfazer a noção de que a literatura seja um pretexto para se ensinar língua portuguesa, especificamente gramática. Entretanto, na maioria dos casos, há uma deficiência de leitura literária no meio escolar.

Pensando nessas considerações, é que este trabalho se volta para uma possibilidade de perceber na obra literária possibilidades de letramento a fim de que o leitor tenha compreensão das práticas sociais permitidas por meio do estudo de literatura. Claro que outras disciplinas também possibilitam a desenvoltura desse fazer social. Entretanto,

Sabemos que em literatura temos uma mensagem ética, política, religiosa ou mais geralmente social só tem eficiência quando for reduzida a estrutura literária, a forma ordenadora. Tais mensagens são válidas com quaisquer outras, e não podem ser proscritas; mas sua validade depende da forma que lhes dá existência com um certo tipo de objeto. (CANDIDO, 1995, p. 250).

Considerando a literatura, a obra de Bernardo Élis (1981) é rica em detalhes que nos evidenciam os dilemas do sertanejo em suas mais variadas formas. Especificamente no conto “Caminhão de Arroz", a leitura de forma mais enfática mostra-nos que além dos conhecimentos relacionados à língua do sertanejo, há também uma abordagem social e ontológica. O ser humano pode ser lido em sua total composição, quer seja interior como exterior. Esta é a proposta deste estudo no intuito de que o leitor viva uma experiência literária, percebendo, no conto "Caminhão de Arroz", possibilidades para uma aquisição interpretativa sobre letramento social. Refletindo, desta forma, sobre a ação epistemológica de si e do meio social que o cerca. 


\section{Literatura e prática sociais: vivências literárias}

Nas últimas décadas, o ensino de literatura tem passado por várias transformações, entretanto em muitos momentos de forma negativa. Aproveita-se da literatura, principalmente por meio de excertos, para se trabalhar questões gramaticais da língua portuguesa, quando muito a predominância de algum recurso estilístico. Indaga-se, então, quais os motivos que deveriam despertar o interesse do leitor em relação à literatura? Teria a literatura algum objetivo específico?

Se pensarmos nas palavras de Antônio Candido (1995) quando se refere ao processo de humanização que a literatura pode proporcionar ao ser, pode-se compreender, assim, que uma das funções da literatura enquanto arte seria "humanizar". Humanizar quem é humano? Teria o ser humano se desumanizado em seu processo histórico? O autor deixa claro que entende:

[...] por humanização [...] o processo que confirma no homem aqueles traços que reputamos essenciais, como o exercício de reflexão, a aquisição do saber, a boa disposição para com o próximo, o afirmamento das emoções, a capacidade de penetrar nos problemas da vida, o senso da beleza, a percepção da complexidade do mundo e dos seres, o cultivo do humor. (CANDIDO, 1995, p. 249).

Vê-se assim que há um entrelaçamento entre as circunstâncias da vida, entre as situações problemáticas - quem sabe existenciais - do viver de cada ser humano, quer sejam interiores quanto exteriores. Além disso, há nítida definição de relações sociais, interações que permeiam a convivência em grupo e com o ambiente. Dessa forma, “[...] A literatura desenvolve em nós a quota de humanidade na medida em que nos torna mais compreensivos e abertos para natureza, a sociedade, o semelhante." (CANDIDO, 1995, p. 249).

Relacionando-se as definições de literatura com as circunstâncias existenciais da vida, por meio dos pensamentos teóricos de Antônio Candido (1995), entende-se que o conceito literário tem uma função ontológica, penetra o íntimo do ser por meio de palavras que se dissolvem em imagens e transfiguram-se em arquétipos calcados e (res)guardados no interior do ser humano. Basta levarmos em considerações os ideais coletivos, os medos e sonhos que fazem parte da história da humanidade.

Dadas essas considerações a respeito da literatura, o que se percebe no contexto atual, quando se aborda o ensino dessa disciplina é uma verdadeira contradição:

[...] Literatura tem se tornado cada vez mais rarefeita no âmbito escolar, como bem observou Regina Zilberman (2003, p. 258) seja porque diluída em meio aos vários tipos de discursos ou de textos, seja porque tem sido substituída por resumos, compilações, etc. (BRASIL, 2006, p. 55).

Aqui se torna clara, de acordo com o trecho citado acima, a defasagem pela qual passa o ensino de literatura. As políticas educacionais parecem não se interessar pelo ensino de literatura. Não se apropria da proposta de Antônio Candido (1995) de se perceber o processo de humanização que a literatura provoca no leitor. Se os próprios documentos oficiais do 
governo atestam a fragilidade desta disciplina, pode-se entender que as situações "reais" no sistema educacional brasileiro podem estar em decadência ainda maior. Daí que "[...] faz-se necessário e urgente o letramento literário: empreender esforços no sentido de dotar o educando de capacidade de se apropriar da literatura, tendo dela a experiência literária”. (BRASIL, 2006, p. 55).

Vamos entender "experiência literária" como o entrosamento autor-leitor-obra-contexto a fim de que haja uma reflexão tanto de si mesmo como do meio social. Nesse processo de reflexão literária, reforça-se o caráter político embutido na literatura. Há uma ideologia predominante expressa por meio de um discurso, "[...] visto que nenhum discurso é inocente, não se pode estudar a literatura sem relacioná-la com questões políticas e culturais" (JAMEL, 2016, p. 202).

Talvez uma das dificuldades - em relação ao ensino de literatura - apresentadas no decorrer deste texto seja a falta de interação entre literatura, política e cultura. Nesse sentido, o que se enfatiza por meio dessas considerações é um ensino de literatura pautado em práticas sociais vivenciadas em todos os contextos possíveis, o que, obviamente, poderá favorecer uma interpretação mais adequada tanto da obra quanto do contexto em que vive o leitor. "[...] o ensino da literatura seria uma alternativa enriquecedora das experiências mais comuns do aluno. Teria um papel formador e não apenas informativo.” (OSAKABE, 2012, p. 30). Concordando ainda com a necessidade de se (re)pensar o fazer literário em sala de aula, Oliveira (2014) diz que: "[...] um texto literário é construído como um infinito mosaico de citações, influências e vozes histórico-sociais." (2014, p. 04) Dessa forma, vozes presentes no texto literário em confronto com as vozes de professores e alunos se expressam de forma conflituosa (OLIVEIRA, 2014). Assim, “[...] o letramento literário precisa da escola para se concretizar, isto é, ele demanda um processo educativo específico que a mera prática de leitura de textos literários não consegue sozinha efetivar.” (COSSON; SOUZA, 2011, p. 102).

Considerando o entrosamento autor-obra-contexto-leitor, a produção literária do escritor goiano, Bernardo Élis, permite-nos uma variedade de interpretações, quer seja por meio de uma abordagem ontológica ou social e histórica. Sua obra, de forma geral, se caracteriza por uma representação do que se pode definir como:

[...] literatura de protesto pelo que contribuem em nos chamar a atenção para os dramas sociais dos nossos sertões, no afã do que, com a denúncia, se minorem a miséria e o sofrimento dessas populações marginalizadas. É a literatura a serviço da história, orientando a plataforma da política social [...] (BECHARA, 1991, p. xi).

Diante disso, expressa-se uma oportunidade de humanização (CANDIDO, 1995) que o texto bernardiano apresenta, não somente do ponto de vista social, mas existencial em toda sua plenitude. Os dramas em que as personagens estão submetidas são representações dos dramas do mundo real palpável. A partir dos quais nos é permitida uma compreensão cultural e histórica da região goiana.

As personagens, em sua maioria, se originam da camada rudimentar da sociedade. São os 
não-ditos pela história tradicional. Entretanto, ao considerar a atuação desses personagens, que representam na literatura uma parcela marginalizada pela sociedade, podemos presumir "que a história das 'pessoas comuns', mesmo quando estão envolvidos aspectos explicitamente políticos de sua experiência passada, não se pode ser dissociada das considerações mais amplas da estrutura social e do poder social." (SHARPE, 1992, p. 54).

Claro que tais questões não estão explícitas na obra de Bernardo Élis, mas por meio de uma leitura mais aprofundada, aquela definida como racional em que dialeticamente se faz uma desleitura. Esta compreensão, de acordo Bloom (1995), delimita uma artimanha que nos leva para uma resistência cultural, remédio que desfaz um sentimento de influência porque contradiz originalidade do que nos é imposto, permitindo ao leitor colocar à disposição da leitura suas experiências coloniais. E, além deste aprofundamento, por intermédio também de uma leitura crítica, conforme Martins (1994), pode-se evidenciar a construção da história por parte dos que ficaram marginalizados pela historiografia.

Nelly Alves de Almeida (1970) deixa claro que o modo como o autor cria as personagens “[...] ao apresentá-los, orienta-se através de relatos que transmitem, em suas mensagens, verdades cruéis que não se fixam apenas em sua região, mas expande-se mesmo de forma universal." (1970, p. 60). Além disso, suas personagens representam uma tipologia social. Marcas da existência humana expressas pelas angústias e tragédias da vida (ALMEIDA, 1970). Não representam anseios e ilusões utópicas, pelo contrário, fundem-se no drama da fatalidade. Assim, enquanto

[...] a literatura tem sido um instrumento poderoso de instrução e educação, entrando nos currículos, sendo proposta a cada um como equipamento intelectual e afetivo. Os valores que a sociedade preconiza, ou os que considera prejudiciais, estão presentes nas diversas manifestações da ficção, da poesia e da ação dramática. A literatura confirma e nega, propõe e denuncia, apoia e combate, fornecendo a possibilidade de vivermos dialeticamente os problemas. (CANDIDO, 1995, p. 243).

Retomando as palavras de Candido (1995), na obra de Bernardo Élis (1981), fica explícita a (com)vivência de dilemas e conflitos subjetivos do povo goiano, mas universais em relação ao ser humano. São proposições ontológicas que marcam a vida exterior, porém reflexos do viver interior. Condição exclusiva da literatura, o que pode ser observado no conto "Caminhão de Arroz", do referido autor, publicado na coletânea Caminhos e Descaminhos em 1962, que nos indica a possibilidade de estudo enquanto "experiência literária" (BRASIL, 2006).

\section{Caminhão de Arroz: com sacos ou com pessoas?}

“Caminhão de Arroz" é uma narrativa curta, aproximadamente 6 (seis páginas) de um pequeno livro. Porém essas poucas páginas sugerem uma reflexão aprofundada tanto do ponto de vista sociológico como ontológico. A trama se desenvolve na cidade de Anápolis-Go, quando um caminhão de arroz para em frente a um hotel. Entre as sacas de arroz estão pessoas que se confundem com a carga, dada a situação desumana em que se encontram. No meio desses 
caroneiros, uma personagem se destaca pela maneira desajeitada que procura por sua irmã, uma prostituta rica que mora na cidade. Buscando informações no hotel, quando se vê no espelho do saguão, não se reconhece. O que lhe sobra são gozações e desprezo das pessoas que estão ali.

Fica evidente que a narrativa de Bernardo Élis (1981), aqui representada pelo conto, acaba por expressar os dramas da existência humana daqueles marginalizados pelo poder, especificamente o governamental. É claro também o choque cultural que existe entre moradores da zona rural ao se depararem com o meio urbano. Na verdade, um fato marcante da história de Goiás, por que não dizer do Brasil. Nelly Alves de Almeida (1970) diz que Bernardo Élis

Transporta para suas obras os problemas da liberdade, das lutas, dos jogos a que se submetem os menos favorecidos, do homem ante a vivência do meio, o luxurioso, com perspicácia e talento, com a prudência sábia de quem, nos dias atuais, consegue rejuvenescer o clássico, fazendo ressurgir um humanismo moderno. (ALMEIDA, 1970, p. 40).

Pode-se notar que há uma intenção política em se confrontar esses extremos sociais: meio urbano X meio rural. $\mathrm{Na}$ apresentação do conto, os trechos abaixo relacionados remetem ao questionamento aqui proposto:

As sacas de arroz que o caminhão trazia, umedecidas pelo orvalho, desprendiam um cheiro gostoso de gado calmo ruminando, com repousando [...] contrastava violentamente com o movimento do autos, carroças, homens e meninos, mulheres e velhos, pregões e anúncios daquela rua central de Anápolis, onde se localizava o Hotel Tapir, em cuja porta se estacionou o caminhão. (ÉLIS, 1981, p. 137).

Vários questionamentos podem ser suscitados na citação mencionada acima, desde a calmaria do meio rural à movimentação urbana à qual o autor faz referência. Também fíca evidente o nome do hotel: Tapir palavra originária do tupi que significa anta (CUNHA, 2001). Historicamente, sabe-se que Anápolis se originou no Arraial de Anta (PALACÍN; MORAES, 2001), vemos assim o tom, quem sabe irônico, ao nomear o hotel a partir de um nome indígena. Quem sabe uma problematização que possa despertar a curiosidade do leitor.

Entretanto, o que há na narrativa é uma diversidade social marcada pelo contraste. Entende-se nesse sentido que ao propor uma literatura em que se percebem esses confrontos sociais, "é neste momento que o contato com as diferentes vozes do poder pode causar estranhamentos que leva o sujeito leitor a deslocamentos e posicionamento críticos" (OLIVEIRA, 2014, p. 05). Consequentemente uma (re)visão do processo histórico, já que a prosa literária propicia essa provocação ao leitor, além de possibilitar o letramento literário, uma vez que se pode indagar o texto literário a partir do contexto do leitor (COSSON; SOUZA, 2011). Ainda assim, Oliveira (2014):

Considerando letramento como um fenômeno político, as práticas linguísticas e as formas de conhecimento que ele favorece não podem ser entendidas fora das relações de poder que estruturam a sociedade mais ampla. O contato com 
estas relações de poder [...] sejam elas a literatura canônica, a linguagem padrão ou mesmo a voz da autoridade do professor e até de outros colegas, é fundamental para que os alunos leiam criticamente qualquer texto. Para que desenvolvam uma reflexão dialética da realidade e interroguem a complexidade de suas próprias histórias. Enfim, para que resistam. [...] (OLIVEIRA, 2014, p. 6).

Dadas essas considerações, questionamentos sobre o conto possibilitam diálogos entre professor-aluno-texto. Nesse entremeio de questões que podem ser percebidas no conto, há de se ressalvar que o que chama atenção na narrativa aqui analisada é a personagem sem nome, o que acaba por representar/denunciar aqueles que perderam a condição social de cidadão, é uma pessoa qualquer vitimizada pelo descaso social. É descrita como:

[...] um vulto se mexeu [...] Era uma mulher. Nem nova, nem velha, nessa neutralidade de temo, nesse misterioso ar sem díade das roceiras. Pele requeimada e macilenta, maçãs do rosto salientes, beiços grossos e gretados de poeira, sol e frio; [...] também um papinho não muito no meio do pescoço, assim para uma banda. (ÉLIS, 1981, p. 138-139).

Apenas um vulto que nunca fora à cidade de Anápolis. Não conhecia mais nada além de um "lugarejo feio e sonolento, como tapera" (ÉLIS, 1981, p. 139). Aqui, em algumas referências da parte inicial do conto, há de se perceber a disparidade entre o meio rural e a cidade. Claro que levamos em conta o momento da produção literária - década de 1960 - porém o embate se dá entre condições sociais, o que não se difere da atualidade. Nesse sentido, apesar de o conto ser escrito há mais de 50 anos, as problematizações são vivenciadas no dia a dia. Há uma nítida expressividade das condições sociais que marcaram e ainda marcam a tentativa de sobrevivência das pessoas do campo nas cidades grandes. Se levarmos em conta a função política da literatura, estudá-la nos permite chegar, pelo menos, à compreensão ao questionamento de problemas sociais, isto quando as obras se caracterizam como engajadas. Nas palavras de Coutinho (1999):

Uma literatura de crítica social, em que Bernardo Élis aponta a miséria e a degradação a que ficam sujeitas as populações sertanejas de Goiás, exploradas pelos grandes proprietários de terras, vitimados pela ignorância e pelo pauperismo, mergulhados na superstição. (COUTINHO, 1999, p. 290).

A voz que prevalece é da denúncia social: “[...] a mulher [...] esquiva, indecisa, procurando ajeitar no corpo o vestido amarrotado e sujo, tentando limpar no chão os pés descalços, sem saber se entrava ou não [no hotel]" (ÉLIS, 1981, p. 139). É reconhecível que os elementos estruturais que caracterizam a produção literária são extremamente importantes na construção e análise de uma obra, não há que se questionar tais elementos. Entretanto, não se pretende aqui enveredar por esse viés analítico, como dito, é reconhecível a importância da forma estrutural, mas o que se intenciona vai ao encontro, principalmente, da contextualização da obra, a partir da qual pensa-se provocar epistemologicamente o leitor de forma reflexiva para que se auto perceba no meio social. Assim, considerando propostas de letramento (BRASIL, 2006), a narrativa aqui apresentada nos oferece condições de: 
[...] experimentar a sensação de estranhamento que a elaboração peculiar do texto literário, pelo uso incomum de linguagem, consegue produzir no leitor, o qual, por sua vez, estimulado, contribui com sua própria visão de mundo para a fruição estética. A experiência construída a partir dessa troca de significados possibilita, pois, a ampliação de horizontes, o questionamento do já dado, o encontro da sensibilidade, a reflexão, enfim, um tipo de conhecimento diferente do científico, já que objetivamente não pode ser medido. (BRASIL, 2006, p. 55).

Entretanto, há de se enfatizar o entrosamento professor/aluno/texto literário como possibilidade de envolvimento com as múltiplas significações que a narrativa literária nos permite e que desperta ainda um (re)conhecer de forma mais aprofundada sobre a obra literária e suas representações no contexto em que o aluno está inserido, inter-relacionar-se com a ficção literária como reflexão do existir no meio social.

Nessa concepção, o contexto histórico e sociológico é fundamental no entendimento de determinada obra literária. (Re)conhecendo uma produção literária e os ambientes externos que também lhe fazem parte, vamos entender que "[a] própria literatura se constitui como uma determinada sintomatologia da sociedade e contrapõe essa sintomatologia aos gritos e fícções da cena pública.” (RANCIÈRE, 2015, p. 49).

No conto "Caminhão de Arroz", perceber a "sintomatologia da sociedade" (RANCIÈRE, 2015) se expressa na perturbação em que vive a personagem: “[...] O movimento de Anápolis a atordoava: as casas grandes, a rua calçada, aquele horror de gente indo e vindo, o saguão com o chão brilhante e escorregadio. Será que podia pisar ali? E se levasse um tombo? (ÉLIS, 1981, p. 139).

A dúvida, a insegurança e o medo tomam conta da personagem. O mundo lhe é estranho, tudo lhe é estranho em sua própria terra. "somos uns desterrados em nossa terra" (HOLANDA S.D. apud SCHWARZ, 2003, p. 13). Aqui fica clara a consideração de isolamento social, o que acaba por construir um isolamento individual. O indivíduo se perde em si mesmo. Sérgio Buarque de Holanda (1999), em sua obra Raízes do Brasil, deixa claro que:

No Brasil [...], o desenvolvimento da urbanização - que não resulta unicamente dos meios de comunicação, atraindo vastas áreas rurais para a esfera de influência das cidades - ia acarretar um desequilíbrio social, cujos efeitos permanecem vivos ainda hoje. (HOLANDA, 1999, p. 145).

É o que também pode ser depreendido do conto: “[...] ante a visão da sala, de sua amplitude e limpeza, com os móveis bonitos, os metais polidos, os homens sadios, limpos. Bem melhor que o sertão donde vinha, de estrada poeirenta, dos ranchos pequenos e imundos." (ÉLIS, 1981.p. 138). A falta de equilíbrio social favorece alguns em detrimento de uma grande maioria, o que perdura não só no tempo da narrativa, no tempo em que a narrativa foi escrita assim como na atualidade. $\mathrm{O}$ desenvolvimento intenso de determinada região consequentemente leva a um processo de exclusão de outra.

Contrariando a visão romântica do sertão, o que se percebe aqui é uma forte exploração marcada pelas dificuldades e menosprezo pelos quais vivem o habitante do interior. A cidade, 
referenciada no conto, é o local de estranhamento, da diferença, o que causa na personagem a situação de isolamento.

Quando a mulher entra no hotel, depara-se com uma imagem refletida em um espelho, objeto desconhecido por ela: "[...] Olhou com maior atenção e notou que de dentro desse vão, dessa porta, desse trem esquisito vinha vindo um vulto. Vulto também de mulher, seria?" (ÉLIS, 1981, p. 139). Não tem conhecimento de sua imagem. O si mesmo para ela era desconhecido. Reconhece a feição como familiar, uma irmã que teria ido embora para a cidade de Anápolis e nunca mais havia voltado. “[...] Diziam que era mulher da vida.” (ÉLIS, 1981, p. 140). Nessa procura incessante, indagava a todos:

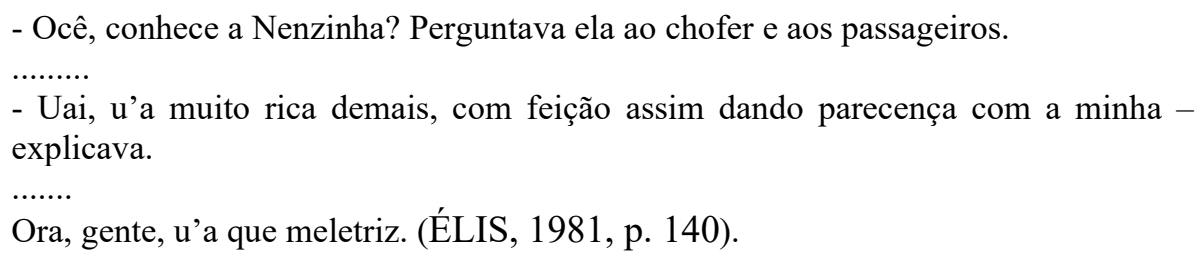

O Impacto que a cidade lhe causa se evidencia como o acesso à riqueza. Sua irmã é rica, mora num palácio, “[...] numa casa mais bonita do que uma igreja. [...]” (ÉLIS, 1981, p. 140). Assim:

Élis foi capaz de apresentar o sertanejo goiano com muita maestria, ao mesmo tempo em que respondia a outra necessidade, a de caricaturar um país que encenava a modernização e mantinha, contraditoriamente, a marca rural devido à estrutura colonial que perdura nos ermos do país e que, por sua vez, decorre do processo de sua ocupação e exploração. (CANEDO; BERGAMO, 2015, p. 2).

A narrativa literária vai então se mostrando como parasita do mundo real (ECO, 1994). Se apropria do contexto, da história vivida e vivenciada pelos marginalizados socialmente. Transfigura-se ao ponto de fazer da arte uma provocação ao leitor, instigá-lo quanto ao meio em que vive.

Ainda em relação ao conto, enquanto a personagem busca pela irmã no saguão do hotel, a figura dentro do espelho - não sabendo que era de si mesma, se destaca como: “[...] Envelhecida, triste, mal vestida! Vestido de chitinha barata, pés no chão, lenço azul na cabeça, brinquinhos de cabacinhas orlados de metal dourado. [...] Mas quede a riqueza, os vestidos bonitos, os sapatos, os cabelos penteados!" (ÉLIS, 1981, p. 140). A imagem que vê não corresponde à perspectiva que tem daquilo que a cidade possa/deveria oferecer. A literatura, nesse sentido, deixa clara a problematização relacionada à região: diversidade social marcada por sonhos e decepções.

Evidencia-se também o espírito capitalista representado ideologicamente pela personagem: "Mas você é tão rica [...]" (ÉLIS, 1981, p. 141), fala para o próprio reflexo - sua irmã. Sair do sertão em busca da cidade marca a ânsia pela conquista econômica; da mesma forma que um brasileiro de qualquer região do país sai para o exterior, principalmente para os países classificados como de primeiro mundo, em busca de nada mais que ascensão econômica. 
Isso demonstra o caráter universal do conto de Élis. São apresentadas situações conflituosas que dizem respeito à ânsia humana.

Ao ver a personagem conversando consigo mesma, o motorista do caminhão "[...] achou aquilo de uma graça imensa. Ora, sim senhor que esses roceiros são umas bestas quadradas [...]” (ÉLIS, 1981, p. 141). Entretanto, quando passa a refletir sobre a condição “[...] sentiu o coração apertar num constrangimento [...] Agora, o que via era uma figura de decepção, de derrota, do desencanto e do desapontamento. [...]" (ÉLIS, 1981, p. 141).

Nesse aspecto, é que vamos compreender de modo mais intenso o porquê de Antônio Candido (1995) se referir à literatura como um fator de humanização. Entretanto, acredita-se que essa função humanizadora que Candido (1995) se refere só se realiza a partir da prática social que permite a reflexão de atitudes como as ocorridas no conto em relação à situação grotesca vivida pela personagem, representando, assim, uma visão ontológica do ser humano. A angústia e o conflito se expressam de forma que se perceba a universalidade da busca incessante do ser humano. Possibilidade que a arte literária pode representar:

[...] Por que não abraçar aquela criatura, não dar-lhe um beijo de conforto e coragem! Por que não ampará-la naquele momento de tamanho desamparo, [...] mas um homem é homem e não deve ser deixar dominar pelo coração, [...] Não fora ele que construíra um mundo tão mau e tão duro. (ÉLIS, 1981, p. 141).

O trecho citado demonstra o momento em que o motorista do caminhão se compadece da situação de menosprezo pelo qual vive a personagem. Porém, ao se reprimir emocionalmente, a atitude do caminhoneiro reforça que é a individualidade que se sobrepõe ao menosprezo social. Os problemas sociais não devem afetar emocionalmente um grupo específico, o compadecimento do motorista demonstra a ignorância de muitos e o sofrimento das minorias. Dessa forma, Almeida (1970) demonstra que é "uma visão de conjunto que abrange os aspectos mais variados: às vezes rude, agreste, ora sociológico e até filosófico" (1970, p. 40) o que caracteriza a obra de Bernardo Élis.

Ao retornar ao caminhão, a roceira fracassada na tentativa de encontrar a irmã "[...] arranhava a madeira, escorregava, agarrava-se mais em cima, erguia as pernas mostrando umas canelas finas e feridentas, uns trajes íntimos imundos e rotos." (ÉLIS, 1981, p. 142). A descrição realça a animalização do ser, em estado de miséria, além de social, humana. Menosprezo, marginalidade e exclusão tão visíveis ao meio social.

O final do conto resume-se à perda da identidade humana, a desconstrução do ser, quando uma personagem secundária diz que: “[...] quem não sabe, até pensa que lá dentro só há sacas de arroz, não é mesmo! As pessoas aí têm tudo de um saco de arroz: a cor, o aspecto, a postura... - De vera! É tudo saco - concordaram." (ÉLIS, 1981, p. 142).

Em relação ao conto aqui apresentado, levar aos alunos obras como as de Bernardo Élis, são oportunidades de conhecimento mais aprofundado sobre as relações sociais de uma determinada época como também possibilidade de se entender que os dilemas vivenciados pelas personagens são da mesma forma vividos no contexto atual. Dessa forma, um local adequado 
para tais reflexões seriam as aulas de literatura.

\section{Considerações finais}

A partir do que foi exposto, avaliando apenas o aspecto sociológico, vamos perceber que existe uma gama de possibilidades de se contextualizar o ensino de literatura a fim de que não fique apenas na leitura de trechos soltos de uma determinada obra literária. Questões como problemas sociais e ontológicos são evidentes nas narrativas de ficção. O que justifica a participação no leitor na reflexão da narrativa. Ao proporcionar oportunidades de leitura em sala de aula em que alunos e professor adentrem ao texto literário reflexivamente, novas formas de conhecimentos podem ser despertadas, considerando que o conhecimento se efetive por meio de práticas sociais.

Dessa forma, o conto traz possibilidades de expressões polifônicas (OLIVEIRA, 2014). "[...] Em uma sala de aula polifônica, alunos e professores relacionam seus horizontes sociais aos horizontes sociais de textos literários, fazendo presente a partir da compreensão do enunciado do texto, sua interpretação. [...]" (OLIVEIRA, 2014, p. 05). Acredita-se que assim, haja letramento literário.

Nas obras de Bernardo Élis, tais considerações são evidentes. No conto aqui analisado ainda de forma mais acentuada, tendo em vista que o drama vivenciado pela personagem que busca por sua irmã pode ser o drama de muitos seres humanos em busca de conquistas e sonhos. Também se evidencia o processo histórico que marcou a região do Estado de Goiás: o surgimento das cidades como tentativa de modernização, entretanto marcadas pela pobreza e pela miséria daqueles que vêm do meio rural, desassistidos pelo poder Estado.

De forma geral, é uma possibilidade, uma tentativa de mostrar que o ensino de literatura vai muito mais além de pretextos para se estudar gramática da língua, claro que isto é importante, mas não apenas isso, há um vasto campo de estudo. São possibilidades de se vivenciar a prática por meio de uma experiência literária.

\section{Referências}

ALMEIDA, Nelly Alves de. Presença literária de Bernardo Élis: antologia. Goiânia: Oficinas Gráficas da Imprensa da Universidade Federal de Goiás, 1970.

BECHARA, Evanildo. Bernardo Élis: apresentação. In: ÉLIS, Bernardo. Seleta. Organização de Gilberto Mendonça Teles. 3. ed. Rio de Janeiro: José Olympio, 1991, p. VIII-XIV.

BLOOM, Harold. Um mapa da desleitura. Trad. de Thélma Médici Nóbrega. Rio de Janeiro: Imago, 1995.

BRASIL. Linguagem. Códigos e suas tecnologias. Brasília: Ministério da Educação, Secretaria de Educação Básica, 2006. 239 p. (Orientações curriculares para o ensino médio; volume 1).

CANDIDO, Antonio. O direito à literatura. Vários escritos. São Paulo: Duas Cidades, 1995. 
CANEDO, Rogério Max; BERGAMO, Edvaldo. A marginalidade como mote e desfecho de um programa literário nacional: o projeto de escrita do centenário poeta, contista, romancista $\mathrm{e}$ ensaísta Bernardo Élis. In: ABRALIC, 24, 2015. Anais... Belém: UFPA. Disponível em: http://www.abralic.org.br/anais/arquivos/2015_1456107618.pdf. Acesso em: 12/01/2018.

COSON, Rildo; SOUZA, Renata Junqueira de. Letramento literário: uma proposta para a sala de aula. Acervo digital da Unesp, São Paulo, 15 ago. 2011. Disponível em: https://acervodigital.unesp.br/handle/123456789/40143?locale $=$ pt_BR\&contrast $=$. Acesso em: 20/01/2018.

COUTINHO, Afrânio. A literatura no Brasil: era modernista. 5. ed. São Paulo: Global, 1999.

CUNHA, Antônio Geraldo da. Dicionário etimológico nova fronteira da língua portuguesa. 2. ed. Rio de Janeiro: Nova Fronteira, 2001.

ECO, Umberto. Seis passeios pelos bosques da ficção. São Paulo: Companhia das Letras, 1994.

ÉLIS, Bernardo. Caminhos dos gerais: contos. Rio de Janeiro: Civilização Brasileira, 1981.

HOLANDA, Sergio Buarque de. Raizes do Brasil. 26. ed. São Paulo: Companhia das Letras, 1999.

JAMEL, Maíra Contrucci. História, literatura e memória: uma perspectiva pós-modernista de O Retrato do Rei, de Ana Miranda. Fronteiraz, São Paulo, n. 16, p. 199-216, jul. 2016. Disponível em: https://revistas.pucsp.br/index.php/fronteiraz/article/viewFile/25596/20189. Acesso em: 10/08/2017.

MARTINS. Maria Helena. O que é leitura. 19. ed. São Paulo, Brasiliense, 1994.

OLIVEIRA, Míria Gomes. O ensino de literatura no ensino médio brasileira: controvérsias, diversidades e polifonia. Revista Portuguesa de Educação. v. 27, n. 1, p. 95-110 2014. Disponível em: http://revistas.rcaap.pt/rpe/article/view/4299. Acesso em: 10/01/2018.

OSAKABE, Haquira. Ensino de gramática e ensino de literatura. In: GERALDI, João Wanderley (Org.) O texto na sala de aula. São Paulo: Anglo, 2012, p. 26-31.

PALACIN, Luís; MORAES, Maria A. de S. História de Goiás. 6. ed. Goiânia: UCG, 2001.

RANCIÈRE, Jacques. A partilha do sensivel: estética e política. 2. ed. São Paulo: EXO experimental org.; Editora 34, 2015.

SCHARWZ, Roberto. Ao vencedor as batatas: forma literária e processo social nos inícios do romance brasileiro. 5. ed. São Paulo: Duas Cidades, 2003.

SHARPE. Jimy. A história vista de baixo. In: BURKE, Peter. (Org.). A escrita da história: novas perspectivas. São Paulo: Unesp, 1992, p. 39-62.

\section{NOTAS DE AUTORIA}

José Elias Pinheiro Neto (joseeliaspinheiro@gmail.com) é doutor pela Universidade de São Paulo, professor no Programa de Pós-Graduação Stricto Sensu em Língua, Literatura e Interculturalidade / Universidade Estadual de Goiás / Câmpus Cora Coralina. Integrante do 
Grupo de pesquisa: Geografia, Literatura e Arte, regularmente cadastrado no CNPq, e dos Grupos de Estudos: Imaginário, Paisagem e Transculturalidade (GEIPaT), com sede na Universidade Federal de Goiás (IESA) e do Espaço, Sujeito e Existência, Dona Alzira, com sede na Universidade Federal de Goiás (LABOTER / IESA).

Antonio Oliveira (professorantoniooliveira@bol.com.br) é mestre em Educação, Linguagens e Tecnologias pela Universidade Estadual de Goiás (2019). Professor contratado da Universidade Estadual de Goiás, professor concursado da Prefeitura Municipal de Guaraíta, Leciona disciplinas de Língua Portuguesa e Língua Inglesa. Como pesquisador atua principalmente nos seguintes temas: tragédia, conflito interior, existência humana, literatura fantástica, metaficção historiográfica, educação.

\section{Como citar esse artigo de acordo com as normas da revista}

PINHEIRO NETO, José Elias; OLIVEIRA, Antonio. Literatura e políticas educacionais: uma abordagem social a partir do conto "Caminhão de arroz" de Bernardo Élis. Anuário de Literatura, Florianópolis, v. 24, n. 2, p. 177-189, 2019.

\section{Contribuição de autoria}

Antonio Oliveira: a contribuição no trabalho foi realizada conjuntamente em todas as etapas, quais sejam: concepção, coleta de dados e análise de dados, elaboração do manuscrito, redação e discussão de resultados.

José Elias Pinheiro Neto: a contribuição no trabalho foi realizada conjuntamente em todas as etapas, quais sejam: concepção, coleta de dados e análise de dados, elaboração do manuscrito, redação e discussão de resultados.

\section{Financiamento}

Não se aplica.

\section{Consentimento de uso de imagem}

Não se aplica.

\section{Aprovação de comitê de ética em pesquisa}

Não se aplica.

\section{Licença de uso}

Este artigo está licenciado sob a Licença Creative Commons CC-BY. Com essa licença você pode compartilhar, adaptar, criar para qualquer fim, desde que atribua a autoria da obra.

\section{Histórico}

Recebido em: 27/02/2019

Revisões requeridas em: 01/10/2019

Aprovado em: 13/10/2019

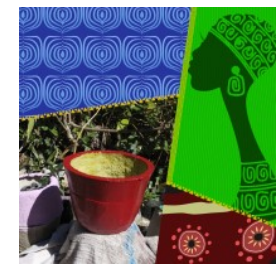

